\title{
Effect of inhaled steroids on airway hyperresponsiveness, sputum eosinophils, and exhaled nitric oxide levels in patients with asthma
}

Elizabeth L J van Rensen, Karin C M Straathof, Maud A Veselic-Charvat, Aeilko H Zwinderman, Elisabeth H Bel, Peter J Sterk

\begin{abstract}
Background-Airway hyperresponsiveness, induced sputum eosinophils, and exhaled nitric oxide (NO) levels have all been proposed as non-invasive markers for monitoring airway inflammation in patients with asthma. The aim of this study was to compare the changes in each of these markers following treatment with inhaled glucocorticosteroids in a single study.
\end{abstract}

Methods-In a randomised, double blind, placebo controlled, parallel study 25 patients with mild asthma (19-34 years, forced expiratory volume in one second $\left(F_{E V}\right)>75 \%$ predicted, concentration of histamine provoking a fall in $\mathrm{FEV}_{1}$ of $20 \%$ or more $\left.\left(\mathbf{P C}_{20}\right)<4 \mathrm{mg} / \mathrm{ml}\right)$ inhaled fluticasone propionate $(500 \mu \mathrm{g}$ twice daily) for four weeks. $\mathbf{P C}_{20}$ to histamine, sputum eosinophil numbers, and exhaled NO levels were determined at weeks 0,2 , and 4 , and two weeks after completing treatment. Sputum was induced by inhalation of hypertonic $(4.5 \%)$ saline and eosinophil counts were expressed as percentage nonsquamous cells. Exhaled NO levels (ppb) were measured by chemiluminescence.

Results-In the steroid treated group there was a significant increase in $\mathbf{P C}_{20}$, decrease in sputum eosinophils, and decrease in exhaled NO levels compared with baseline at weeks 2 and 4 of treatment. Subsequently, each of these variables showed significant worsening during the two week washout period compared with week 4 . These changes were significantly different from those in the placebo group, except for the changes in sputum eosinophils and exhaled NO levels during the washout period. There were no significant correlations between the changes in the three markers in either group at any time.

Conclusions-Treatment of asthmatic subjects with inhaled steroids for four weeks leads to improvements in airway hyperresponsiveness to histamine, eosinophil counts in induced sputum, and exhaled nitric oxide levels. The results suggest that these markers may provide different information when monitoring anti-inflammatory treatment in asthma. (Thorax 1999;54:403-408)

Keywords: airway hyperresponsiveness; asthma; fluticasone propionate; inhaled corticosteroids; nitric oxide; induced sputum
Asthma is an inflammatory disease of the airways associated with airway hyperresponsiveness to various bronchoconstrictor stimuli such as histamine. ${ }^{1}$ The accompanying inflammation is characterised by the presence of inflammatory cells such as $\mathrm{T}$ lymphocytes, neutrophils and eosinophils and their cytokines in the airway mucosa, as demonstrated in bronchial biopsy specimens. ${ }^{23}$ The current treatment of asthmatic patients is based on the belief that reducing airway inflammation is essential, and that control of such inflammation can be indirectly assessed by optimising symptoms and lung function. ${ }^{14}$ However, monitoring airway inflammation more closely by measurement of non-invasive and sensitive markers of inflammation, such as airway hyperresponsiveness, ${ }^{5}$ sputum eosinophils, ${ }^{6}$ or exhaled NO levels, ${ }^{7}$ may provide additional information for assessing asthma control.

Inhaled glucocorticosteroids are currently the most effective treatment for asthma, not only reducing symptoms and airway hyperresponsiveness ${ }^{8}$ but also leading to an improvement in airway inflammation. ${ }^{9}$ However, recent evidence has suggested that such treatment often provides only partial suppression of airway inflammation, as shown by persisting eosinophilic inflammation in the bronchial (sub)mucosa after long term inhaled steroid treatment in some patients. ${ }^{5}$

Among the non-invasive techniques, hypertonic saline induced sputum has been shown to be a reliable method for measuring eosinophilic airways inflammation. ${ }^{61011}$ The number of eosinophils in sputum is associated with asthma severity ${ }^{10}$ and decreases following treatment with inhaled steroids. ${ }^{12}$ In addition, nitric oxide levels in exhaled air have also been proposed as a marker for disease severity in asthma. ${ }^{713}$ Indeed, inhaled glucocorticosteroids decrease the levels of exhaled $\mathrm{NO}$ in patients with asthma ${ }^{14}$ in a dose dependent way. ${ }^{15}$

Although the effects of inhaled steroids on sputum eosinophils and exhaled NO have been well established, comparative analysis is required before any of these markers can be recommended in the monitoring of asthma treatment. In the present study we investigated treatment induced changes in airway hyperresponsiveness, sputum eosinophils, and exhaled NO levels in asthma. To that end we performed histamine challenge, induced sputum, and exhaled NO measurements before, during, and after four weeks of treatment with 
Table 1 Characteristics of the subjects

\begin{tabular}{|c|c|c|c|c|c|c|}
\hline Subject no & Sex & Age (years) & $\begin{array}{l}F E V_{1} \\
\text { (\% pred) }\end{array}$ & $P C_{20}(\mathrm{mg} / \mathrm{ml})$ & $\begin{array}{l}\text { Eosinophils } \\
(\%)\end{array}$ & $N O(p p b)$ \\
\hline \multicolumn{7}{|c|}{ Steroid treated group } \\
\hline 1 & M & 24 & 77 & 0.07 & 1.4 & 5.85 \\
\hline 2 & $\mathrm{M}$ & 24 & 104 & 0.37 & 3.8 & 10.75 \\
\hline 3 & M & 21 & 104 & 0.39 & 5.8 & 11.81 \\
\hline 4 & $\mathrm{~F}$ & 23 & 88 & 0.55 & 7.6 & 5.28 \\
\hline 5 & $\mathrm{~F}$ & 20 & 83 & 0.71 & 4.0 & 3.42 \\
\hline 6 & $M$ & 24 & 103 & 0.72 & 0.0 & 8.24 \\
\hline 7 & M & 23 & 94 & 1.29 & 3.6 & 10.21 \\
\hline 8 & $\mathrm{~F}$ & 24 & 101 & 1.81 & 0.2 & 7.25 \\
\hline 9 & $\mathrm{~F}$ & 21 & 99 & 2.05 & NA & 2.17 \\
\hline 10 & M & 28 & 104 & 2.54 & 3.4 & 2.15 \\
\hline 11 & $\mathrm{~F}$ & 21 & 98 & 3.14 & 1.4 & 3.92 \\
\hline \multirow[t]{2}{*}{12} & $\mathrm{M}$ & 27 & 99 & 3.14 & 0.2 & 4.62 \\
\hline & & $23.3(2.4) \dagger$ & $96.2(9.0) \dagger$ & $0.91(1.62)^{\star}$ & $2.85(2.46) \dagger$ & $6.30(3.34) \dagger$ \\
\hline \multicolumn{7}{|c|}{ Placebo group } \\
\hline 13 & $\mathrm{M}$ & 24 & 82 & 0.11 & 21.2 & 13.41 \\
\hline 14 & $\mathrm{~F}$ & 21 & 108 & 0.11 & 0.0 & 6.57 \\
\hline 15 & M & 29 & 111 & 0.14 & 24.6 & 12.05 \\
\hline 16 & M & 34 & 83 & 0.30 & 0.0 & 4.17 \\
\hline 17 & M & 21 & 98 & 0.46 & 1.6 & 13.40 \\
\hline 18 & M & 24 & 80 & 0.54 & NA & 14.08 \\
\hline 19 & $M$ & 25 & 86 & 0.73 & 0.0 & 3.26 \\
\hline 20 & M & 24 & 98 & 0.77 & 1.8 & 4.22 \\
\hline 21 & $\mathrm{~F}$ & 24 & 106 & 0.89 & 3.2 & 2.48 \\
\hline 22 & $M$ & 28 & 90 & 1.00 & 1.2 & 3.36 \\
\hline 23 & $\mathrm{~F}$ & 28 & 106 & 1.20 & NA & 5.05 \\
\hline 24 & $\mathrm{~F}$ & 25 & 98 & 1.51 & 0.0 & 5.82 \\
\hline \multirow[t]{2}{*}{25} & $\mathrm{M}$ & 19 & 97 & 1.70 & 0.4 & 9.26 \\
\hline & & $25.1(3.9) \dagger$ & $95.6(10.6) \dagger$ & $0.52(1.38)^{\star}$ & $4.91(8.98) \dagger$ & $7.47(4.37) \dagger$ \\
\hline
\end{tabular}

$\mathrm{FEV}_{1}=$ forced expiratory volume in one second; $\mathrm{PC}_{20}=$ provocative concentration of histamine causing a $20 \%$ fall in $\mathrm{FEV}_{1} ; \mathrm{NO}=$ exhaled nitric oxide; $\mathrm{NA}=$ not applicable.

${ }^{\star}$ Geometric mean (SD) in doubling doses.

tMean (SD).

fluticasone propionate or placebo in steroid naive patients with asthma.

\section{Methods}

SUBJECTS

Twenty five non-smoking atopic patients (16 men, age range 19-34 years) with mild persistent asthma ${ }^{1}$ volunteered to participate in the study (table 1). Symptoms of episodic chest tightness and wheezing were treated by ondemand usage of inhaled salbutamol alone, which was discontinued at least eight hours before the measurements. Two weeks before the study all subjects were free from symptoms of respiratory tract infection. Atopy was indicated by a positive skin prick test $(>3 \mathrm{~mm}$ weal) to one or more of 10 common airborne allergen extracts (Vivodiagnost, ALK, The Netherlands). The forced expiratory volume in one second $\left(\mathrm{FEV}_{1}\right)$ was more than $75 \%$ of the predicted value ${ }^{16}$ and all subjects were hyperresponsive to inhaled histamine (provocative concentration causing a fall in $\mathrm{FEV}_{1}$ of $20 \%$ or more $\left(\mathrm{PC}_{20}\right)$ of $\left.<4 \mathrm{mg} / \mathrm{ml}\right) .{ }^{17}$ The study was approved by the medical ethics committee of the Leiden University Medical Center and

Table 2 Airway hyperresponsiveness, sputum eosinophils and exhaled nitric oxide (NO) levels during and after steroid and placebo treatment

\begin{tabular}{lllll}
\hline & Baseline & Week 2 & Week 4 & Washout \\
\hline Steroid group & & & & \\
PC $_{20}(\mathrm{mg} / \mathrm{ml})$ & $0.91(1.62)$ & $3.19(1.54)^{\star}$ & $3.67(1.05)^{\star}$ & $0.93(1.50) \dagger$ \\
Eosinophils (\%) & $2.85(2.46)$ & $0.68(0.94)^{\star}$ & $0.44(0.56)^{\star}$ & $8.14(7.58) \dagger$ \\
NO (ppb) & $6.30(3.34)$ & $1.52(1.28)^{\star}$ & $1.43(0.86)^{\star}$ & $5.22(4.20) \dagger$ \\
Placebo group & & & & \\
PC $_{20}(\mathrm{mg} / \mathrm{ml})$ & $0.52(1.38)$ & $0.64(1.21)$ & $0.59(1.86)$ & $0.66(1.26)$ \\
Eosinophils (\%) & $4.91(8.98)$ & $4.62(6.04)$ & $5.74(5.25)$ & $8.69(9.87)$ \\
NO (ppb) & $7.47(4.37)$ & $7.27(5.38)$ & $5.97(3.42)$ & $7.14(5.59)$ \\
\hline
\end{tabular}

$\mathrm{PC}_{20}$ expressed as geometric mean (SD) in doubling doses; sputum eosinophil counts and exhaled NO levels expressed as mean (SD).

${ }^{\star} \mathrm{p}<0.01$ compared with baseline.

$\mathrm{tp}<0.03$ compared with week 4 . written informed consent was obtained from all volunteers.

DESIGN OF STUDY

The study was of a randomised, double blind, placebo controlled, parallel design. During screening the selection criteria were checked for all subjects. Before entering the treatment period baseline values of $\mathrm{PC}_{20}$ histamine and percentage eosinophils in induced sputum were determined. These two measurements were carried out on two separate days with a 2-4 day interval between them. Prior to histamine challenge and sputum induction, baseline values of $\mathrm{FEV}_{1}$ and exhaled $\mathrm{NO}$ were recorded. This sequence of measurements was used at all time points during the study.

Immediately after the second baseline visit the subjects were treated with inhaled fluticasone propionate $(500 \mu \mathrm{g}$ twice daily) or placebo for a period of four weeks. The measurement of $\mathrm{PC}_{20}$ histamine, sputum eosinophils, $\mathrm{FEV}_{1}$, and exhaled NO were repeated during the treatment period (at weeks 2 and 4 ) and during the washout period at two weeks after the treatment period.

\section{HISTAMINE CHALLENGE}

Histamine challenges were performed according to a standardised methodology. ${ }^{17}$ Histamine-di-phosphate (Sigma Chemicals, St Louis, MO, USA) in phosphate buffered saline (PBS) was stored at $4^{\circ} \mathrm{C}$ and administered at room temperature. Doubling concentrations between 0.06 and $16 \mathrm{mg} / \mathrm{ml}$ were used. The aerosols were generated by a DeVilbiss 646 nebuliser (output $0.13 \mathrm{ml} / \mathrm{min}$ ), connected to an inspiratory and expiratory valve box with an expiratory aerosol filter (Pall Ultipor BB50T). Each dose was inhaled through the mouth by tidal breathing for two minutes at five minute intervals with the nose clipped. ${ }^{17}$

The airway responses to the inhaled aerosols were measured using $\mathrm{FEV}_{1}$, recorded by a dry rolling seal spirometer (Morgan Spiroflow, Morgan UK) and monitored on-line by a personal computer with a special software program. Before each test $\mathrm{FEV}_{1}$ was measured in triplicate for calculation of mean baseline levels. ${ }^{17}$ The airway response was recorded at 30 and 90 seconds after each dose. After each inhalation the lowest technically satisfactory $\mathrm{FEV}_{1}$ value was applied in the analysis to calculate the percentage fall in $\mathrm{FEV}_{1}$ from baseline. The test was discontinued if $\mathrm{FEV}_{1}$ decreased by $20 \%$ or more. The $\mathrm{PC}_{20}$ was calculated by log-linear interpolation of the final two data points.

\section{SPUTUM INDUCTION}

Sputum was induced and processed by the so called full sample method ${ }^{18}$ according to a protocol that has been validated in our laboratory. ${ }^{6}$ Hypertonic saline aerosols $(\mathrm{NaCl} 4.5 \%)$ were generated at room temperature by a DeVilbiss Ultraneb 2000 ultrasonic nebuliser with a calibrated particle size (MMAD $4.5 \mu \mathrm{m}$ ) at maximal output $(2.5 \mathrm{ml} / \mathrm{min})$. The aerosols were administered to the subjects through a $100 \mathrm{~cm}$ long tube with an internal diameter of $22 \mathrm{~mm}$ 


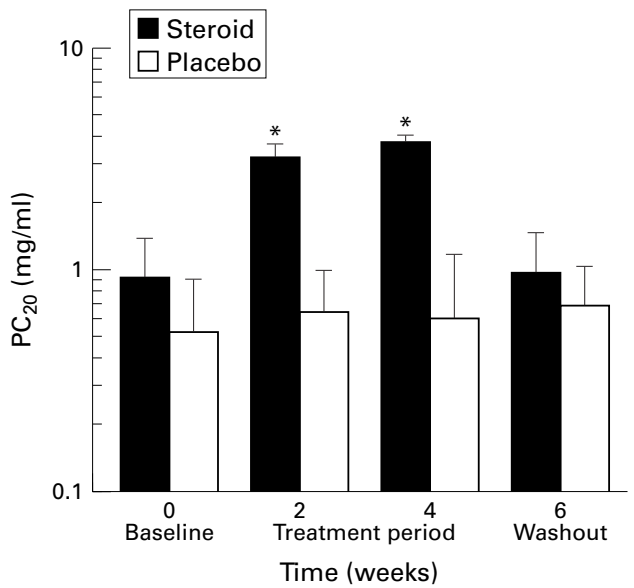

Figure 1 Airway hyperresponsiveness to histamine $\left(P C_{20}\right)$ at baseline, at weeks 2 and 4 of treatment, and after two weeks of washout in the steroid treated (closed bars) and placebo groups (open bars) shown as geometric mean doubling doses; ${ }^{\star}$ significant difference between the two groups.

and inhaled via the mouth through a two way valve (No. 2700; Hans-Rudolph, Kansas City, MO, USA) with the nose clipped. Before inhalation of the aerosols baseline $\mathrm{FEV}_{1}$ was recorded and, for safety reasons, $400 \mu \mathrm{g}$ salbutamol was administered through a metered dose inhaler (Volumatic). The subjects then inhaled hypertonic saline aerosols during $2 \times 5$ minute and $1 \times 10$ minute intervals. After each inhalation, or as soon as the subjects started coughing, they were asked to blow their nose, to rinse their mouth and throat with water, and to expectorate sputum into a clean plastic container by coughing. After testing, $\mathrm{FEV}_{1}$ was measured and salbutamol was administered if needed.

\section{SPUTUM PROCESSING AND CELL DIFFERENTIAL} COUNTS

The volume of the induced sputum samples was determined and mixed with an equal volume of $0.1 \%$ sputolysin (dithiotreitol, Calbiochem, USA). ${ }^{6}$ To ensure complete homogenisation the samples were placed in a shaking water bath at $37^{\circ} \mathrm{C}$ for 15 minutes and then gently mixed. The homogenised sputum was centrifuged $(350 \mathrm{~g})$ for 10 minutes at room

Table 3 Changes in airway hyperresponsiveness, sputum eosinophil counts, and exhaled NO levels between steroid and placebo treatment groups

\begin{tabular}{lll}
\hline & Baseline - Week 4 & Week 4 - Washout \\
\hline$\Delta \mathrm{PC}_{20}(\mathrm{mg} / \mathrm{ml})$ & & \\
$\quad$ Steroid & $2.01(1.60)$ & $-1.75(1.17)$ \\
Placebo & $0.19(0.97)$ & $0.17(1.15)$ \\
$95 \%$ CI & 0.483 to 2.034 & -2.066 to 0.583 \\
p value & 0.003 & 0.001 \\
$\Delta$ Sputum eosinophils $(\%)$ & \\
$\quad$ Steroid & $-2.46(2.52)$ & $6.13(6.37)$ \\
Placebo & $1.25(6.30)$ & $2.95(8.48)$ \\
95\% CI & -8.180 to 0.755 & -4.125 to 10.496 \\
p value & 0.098 & 0.37 \\
$\Delta$ Exhaled NO (ppb) & & \\
Steroid & $-4.88(3.13)$ & $3.65(3.60)$ \\
Placebo & $-1.50(1.91)$ & $1.17(3.27)$ \\
95\% CI & -5.571 to -1.175 & -0.600 to 5.566 \\
p value & 0.005 & 0.11 \\
\hline
\end{tabular}

Changes in $\mathrm{PC}_{20}$ expressed as geometric mean (SD) in doubling doses; changes in sputum eosinophil counts and exhaled NO levels expressed as mean (SD). temperature. The cell pellet was resuspended in PBS to a final volume of 2-5 $\mathrm{ml}$, then filtered through a gauze (pore size approximately $1 \mathrm{~mm}$ ) to remove clumps. Total cell counts were performed in a haemacytometer (Tamson, Zoetermeer, The Netherlands). The sample was then diluted with PBS to a final concentration of $\pm 0.3 \times 10^{6}$ cells $/ \mathrm{ml}$ which was used for preparation of the cytocentrifuge slides $(1500 \mathrm{rpm}$, three minutes, $50 \mu \mathrm{l} / \mathrm{slide}$; Shandon 3, Life Sciences International, Veldhoven, The Netherlands).

Differential counts of eosinophils, neutrophils, lymphocytes, macrophages, epithelial and squamous cells were performed on DiffQuik stained cytospins by a qualified cytopathologist. To correct for the variable salivary contamination, differential leucocyte and cylindrical epithelial cell counts were expressed as a percentage of 250 nucleated cells, excluding squamous cells. For each sample differential cell counts were performed twice by the same observer and the mean values were used in the analysis. A sputum sample was considered adequate when the percentage squamous cells was less than $80 \%$. The reproducibility of the sputum cell counts obtained by this method has been shown to be satisfactory. ${ }^{6}$ To ensure a blind analysis of the sputum samples all cytocentrifuge slides were coded before analysis by an investigator who was not involved in the counting.

\section{EXHALED NO}

Exhaled NO levels were measured by a chemiluminescence analyser (Sievers NOA 270B) according to a standardised procedure ${ }^{7}$ which has previously been used by our laboratory. ${ }^{19}$ The subjects were connected to a closed system to avoid contamination of the measurements with ambient NO. Pressurised air with a low NO concentration $(<1 \mathrm{ppb})$ was administered through a 150 litre reservoir connected to the inspiratory side of a Hans-Rudolph three way valve. The subjects performed a slow vital capacity manoeuvre with a constant expiratory flow of $10 \mathrm{l} / \mathrm{min}$ against an expiratory resistance of 3-4 cm $\mathrm{H}_{2} \mathrm{O}$. The expiratory NO concentration was sampled continuously from the centre of the mouthpiece at a flow rate of $440 \mathrm{ml} / \mathrm{min}$ and the average concentration (in parts per billion; ppb) was determined for a period of 10 seconds. $^{7}$ Baseline values of exhaled NO were obtained from the mean values of the two NO measurements recorded before histamine challenge and sputum induction because their reproducibility was good (intraclass correlation coefficient, $R_{\mathrm{i}}>0.92$ ).

ANALYSIS OF DATA

$\mathrm{PC}_{20}$ was $\log$ transformed before statistical analysis and expressed as geometric mean (SD) doubling doses. Based on their close to normal distribution, the percentage of eosinophils in sputum and the levels of exhaled NO were expressed as mean (SD). To test for differences between and within the treatment groups in general, multivariate analysis of variance (MANOVA) was applied for $\mathrm{FEV}_{1}$ and log $\mathrm{PC}_{20}$, whilst the Kruskal-Wallis test was used 


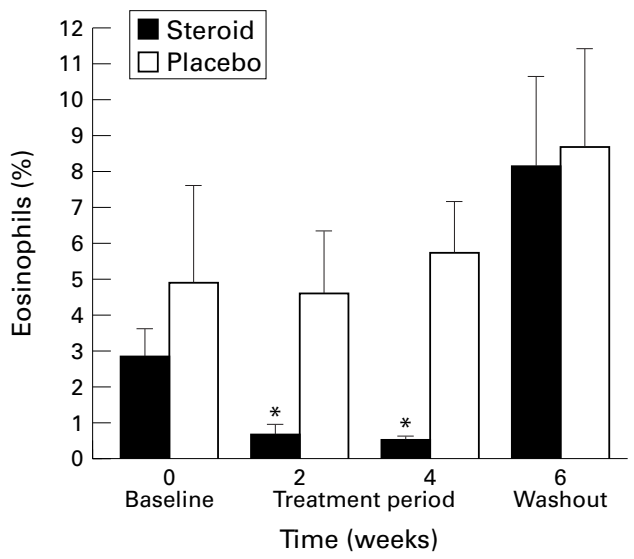

Figure 2 Mean eosinophil counts in induced sputum at baseline, at weeks 2 and 4 of treatment, and after two weeks of washout in the steroid treated (closed bars) and placebo groups (open bars); *significant difference between the two groups.

for sputum eosinophils and exhaled NO. The changes in $\mathrm{PC}_{20}$ (expressed in doubling doses), sputum eosinophils, and exhaled NO levels within each treatment group were analysed using the Student's paired $t$ test whilst changes in $\mathrm{PC}_{20}$, sputum eosinophils, and exhaled NO levels between both groups were tested using the Student's unpaired $t$ test, providing the 95\% confidence intervals (95\% CI). Finally, Pearson correlation analysis was used to examine the relationship between the changes in $\mathrm{PC}_{20}$, sputum eosinophils, and exhaled levels of NO. The results were considered significant if the $\mathrm{p}$ value was $<0.05$. All statistical analyses were performed using the SPSS program.

\section{Results}

Three of the subjects dropped out during the washout period between weeks 4 and 6 because of a history of respiratory tract infection (nos 5 and 6) or because they were taking an antihistamine (no. 11). Three subjects (nos 9, 18 and 23) did not produce adequate sputum at baseline, whilst subjects 21 and 7 were not able to produce sputum at week 2 and week 4, respectively. These time points were handled as missing data.

\section{LUNG FUNCTION AND HISTAMINE CHALLENGE} At baseline there were no significant differences in $\mathrm{FEV}_{1}$ and $\mathrm{PC}_{20}$ between the groups ( $>0.19$; table 1$)$. During the study there were no significant changes in $\mathrm{FEV}_{1}$ in the two groups ( $p>0.96$, MANOVA). In the placebo group there were no significant changes in $\mathrm{PC}_{20}$ ( $\mathrm{p}=0.92$, MANOVA) while in the steroid treated group $\mathrm{PC}_{20}$ increased significantly at week 4 compared with baseline values (mean change 2.01 (95\% CI 0.683 to 2.090 ); p = 0.001 ; fig 1). After a two week washout period $\mathrm{PC}_{20}$ decreased again compared with week 4 by -1.75 ( -1.831 to -0.582$)$ doubling doses $(\mathrm{p}=$ 0.002 ; table 2 , fig 1 ). These changes were significantly different from the changes in the placebo group ( $\mathrm{p}<0.003$; table 3$)$.

SPUTUM EOSINOPHILS

The mean (SD) percentage of squamous cells in this study was $33.4(17.6) \%$. Baseline

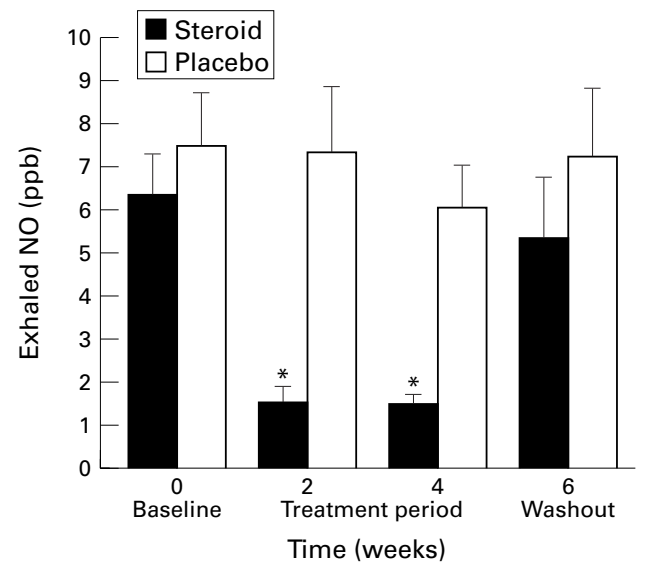

Figure 3 Mean levels of exhaled nitric oxide (NO) at baseline, at weeks 2 and 4 of treatment, and after two week of washout in the steroid treated (closed bars) and placebo groups (open bars); *significant difference between the two groups.

sputum eosinophils were not significantly different in the two groups ( $p=0.31$; table 1$)$. There were no significant changes in sputum eosinophils within the placebo group $(\mathrm{p}=0.85$, MANOVA), but in the steroid treated group a significant decrease in sputum eosinophils was observed compared with baseline values (mean change at week $4-2.46$ (95\% CI -4.260 to $-0.660) \%$; $p=0.01$ ) with a subsequent worsening in the washout period compared with week 4 (mean change 6.13 (95\% CI 0.804 to 11.459$) \% ; p=0.03$; table 2 , fig 2 ). The changes in sputum eosinophils were not significantly different between the two groups when baseline values were compared with week 4 , or week 4 values were compared with those in the washout period (table 3 ).

EXHALED NO

At baseline exhaled NO levels were not significantly different in the two groups $(\mathrm{p}=0.55$; table 1). During the study there were no significant changes in exhaled NO levels in the placebo group ( $p=0.54$, MANOVA; table 2 ) but in the steroid treated group the levels of exhaled NO decreased significantly at week 4 compared with baseline values with a mean change of -4.88 (95\% CI -6.862 to -2.892$)$ $\mathrm{ppb}(\mathrm{p}<0.001)$, with a subsequent increase during the washout period compared with

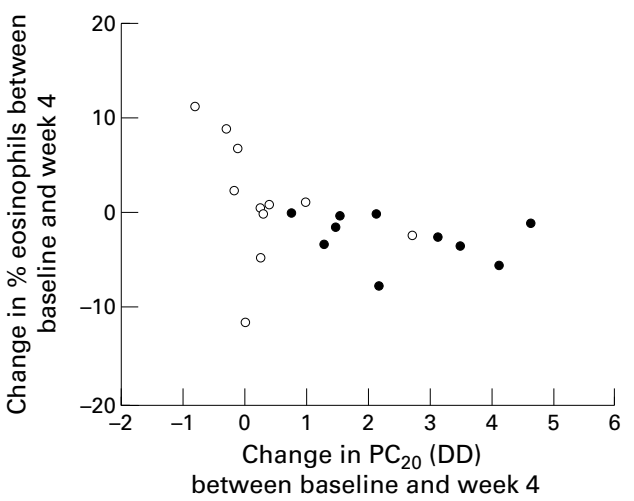

Figure 4 Relationship between the change in sputum eosinophils and the change in $P C_{20}$ histamine at week 4 compared with baseline $(\bullet$ steroid group; $\bigcirc$ placebo group). 


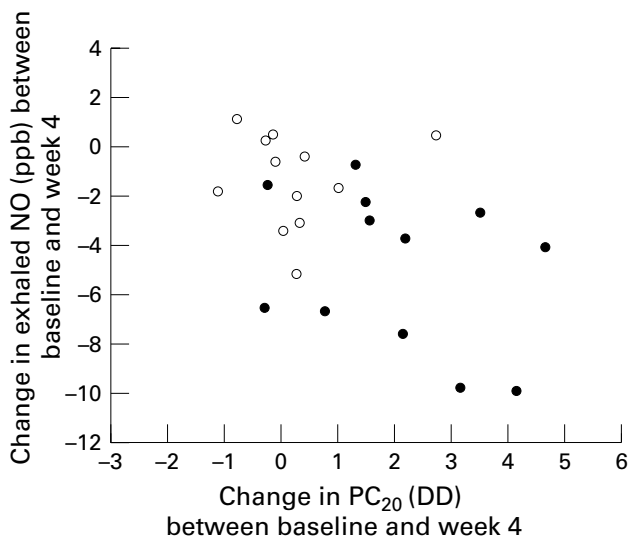

Figure 5 Relationship between the change in exhaled NO levels and the change in $P_{20}$ histamine at week 4 compared with baseline ( $\bullet$ steroid group; $\circ$ placebo group).

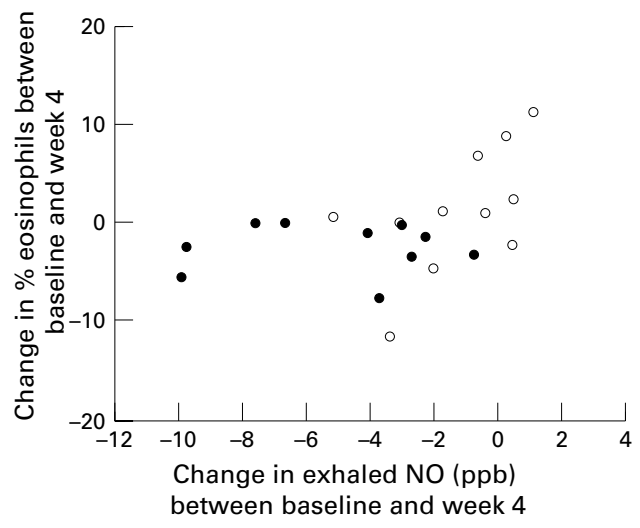

Figure 6 Relationship between the change in sputum eosinophil numbers and the change in exhaled NO levels at week 4 compared with baseline ( steroid group; $\circ$ placebo group).

week 4 of 3.65 (95\% CI 0.882 to 6.423 ) ppb ( $p=0.016$; table 2 , fig 3 ). These changes in exhaled NO levels were significantly different from the changes in the placebo group between baseline and week $4(\mathrm{p}=0.005$; table 3$)$.

RELATIONSHIPS BETWEEN CHANGES IN

PARAMETERS

Within the steroid group there were no significant correlations between the changes in $\mathrm{PC}_{20}$, sputum eosinophils, and exhaled $\mathrm{NO}$ at any time point (Pearson's $r<0.56, \mathrm{p}>0.15$; figs 4-6).

\section{Discussion}

The results of this study indicate that four weeks of treatment with inhaled steroids leads to improvements in airway hyperresponsiveness, sputum eosinophil numbers, and levels of exhaled $\mathrm{NO}$ in patients with mild atopic asthma. In addition, it appears that the improvements in these markers are lost two weeks after cessation of treatment. This suggests that each of these markers may be useful for monitoring patients with asthma, even though there might be small differences between the markers in their earliest response to anti-inflammatory treatment.

To our knowledge this is the first study to compare the treatment induced changes in airway hyperresponsiveness to histamine, eosino- phil counts in induced sputum, and exhaled NO levels in a group of asthmatic patients. Our study confirms and extends the results of others who have shown the beneficial effect of glucocorticosteroids on each of these markers separately. Like Kraan et al, we found an improvement of two doubling doses in airway hyperresponsiveness after four weeks of treatment with inhaled steroids. ${ }^{20}$ Furthermore, our findings are in agreement with those of Keatings et $a l^{12}$ and Kharitonov et $a l^{14}$ who demonstrated a decrease in sputum eosinophils and exhaled NO levels, respectively, after treatment with inhaled steroids.

Although cross sectional relationships between airway hyperresponsiveness, sputum eosinophils, and exhaled NO levels in patients with asthma have been reported previously, ${ }^{10}{ }^{21}$ only limited data are available on the comparison of within subject changes in these markers during treatment follow up. Our results are in agreement with those of Baraldi et al who also failed to find a correlation between steroid induced changes in $\mathrm{PD}_{20}$ and sputum eosinophils. ${ }^{22}$ The absence of such relationships may reflect the partially distinct pathophysiological backgrounds of these markers and might indicate the possible independent complementary clinical information during anti-inflammatory therapy.

We do not believe that our data were influenced by measurement errors since we used validated and reproducible methods. ${ }^{671719}$ All subjects in the study were carefully selected as non-smokers with stable atopic asthma who had not used inhaled steroids for at least one month prior to the study. We chose a relatively high dose of inhaled steroid to ensure an optimal antiinflammatory effect. To avoid carryover effects the histamine challenge for determination of $\mathrm{PC}_{20}$ and the sputum induction were separated by $2-4$ days. Furthermore, exhaled NO levels on these two days appeared to be highly reproducible. Our inability to show a significant improvement in lung function following steroid treatment may be due to the normal baseline levels of $\mathrm{FEV}_{1}$ in our study $(77-111 \%$ of the predicted value).

How can the present findings be interpreted? Firstly, corticosteroids are likely to decrease the percentage of eosinophils in the sputum by reducing the release and subsequent effects of cytokines such as interleukin 5 (IL-5) and granulocyte-macrophage colony-stimulating factor (GM-CSF) on eosinophil infiltration and survival. ${ }^{23-25}$ Secondly, the steroid induced reduction in exhaled NO levels can be explained by the inhibition of inducible $\mathrm{NO}$ synthase (iNOS) expression directly and/or indirectly by reduction in the levels of stimulatory cytokines, for instance in epithelial cells. ${ }^{26}$ Finally, the improvement in the physiological marker $\mathrm{PC}_{20}$ is likely to be due to effects of steroids on the presence and activity of multiple (infiltrative and resident) cells.5 8927 Hence, it may not be surprising that the steroid induced changes in the three markers were not significantly correlated with each other. It would appear that early improvement of 
eosinophils in sputum in response to steroid treatment is somewhat out of phase with the other two markers. However, we believe that this has few implications, given the consistency in the changes between the markers after four weeks of treatment.

What are the clinical implications of the present findings? Treatment according to the current guidelines is based on minimising symptoms and optimising lung function. ${ }^{1}$ However, frequently this fails to provide complete suppression of airway inflammation. ${ }^{5}$ It has been postulated that persistent airway inflammation in asthma leads to airway remodelling and an irreversible loss of lung function. ${ }^{28}{ }^{29}$ This may require the use of more direct markers for monitoring airway inflammation. ${ }^{10}{ }^{30}$ Indeed, a recent study by Sont et al showed that the adjustment of long term inhaled steroid treatment, additionally guided by the level of airway hyperresponsiveness, leads to a significantly better clinical, as well as histological, outcome than treatment guided by symptoms and lung function alone. ${ }^{31}$ Based on the present data, it is now necessary to determine in long term prospective trials whether monitoring sputum eosinophils and/or exhaled NO levels can provide similar benefits in the management of asthma.

The authors thank all the volunteers who participated in this study and Glaxo Wellcome, The Netherlands, for supporting the study with a grant for material expenses.

1 National Institutes of Health, National Heart, Lung, and Blood Institute. Global initiative for asthma. Publication 95-3659, January 1995

2 Djukanovic R, Roche WR, Wilson JW, et al. Mucosal inflammation in asthma. Am Rev Respir Dis 1990;142:43457.

3 Ying S, Humbert M, Barkans J, et al. Expression of IL-4 and IL-5 mRNA and protein product by $\mathrm{CD} 4^{+}$and $\mathrm{CD}^{+} \mathrm{T}$ cells, eosinophils, and mast cells in bronchial biopsies obtained from atopic and nonatopic (intrinsic) asthmatics. f Immunol 1997;158:3539-44.

4 British Thoracic Society. The British guidelines on asthma management: 1995 review and position statement. Thorax 1997;52(Suppl 1):S1-S21.

5 Sont JK, Van Krieken JHJM, Evertse CE, et al. Relationship between the inflammatory infiltrate in bronchial biopsy specimens and clinical severity of asthma in patients treated with inhaled steroids. Thorax 1996;51:496-502.

6 In't Veen JCCM, De Gouw HWFM, Smits HH, et al. Repeatability of cellular and soluble markers of inflammation in induced sputum from patients with asthma. Eur Respir f 1996;9:2441-7.

7 Kharitonov SA, Alving K, Barnes PJ. Exhaled and nasal NO measurements: recommendations. Eur Respir f 1997;10: 1683-93.

8 Barnes PJ. Inhaled glucocorticoids for asthma. N Engl F Med 1995;332:868-75.

9 Trigg CJ, Manolitsas ND, Wang J, et al. Placebo-controlled immunopathologic study of four months of inhaled corticosteroids in asthma. Am f Respir Crit Care Med 1994 150:17-22.
10 Pizzichini E, Pizzichini MMM, Efthimiadis A, et al. Indices of airway inflammation in induced sputum: reproducibility and validity of cell and fluid-phase meas

11 Grootendorst DC, Sont JK, Willems LNA, et al. Comparison of inflammatory cell counts in asthma: induced sputum vs bronchoalveolar lavage and bronchial biopsies. Clin Exp Allergy 1997;27:769-79.

12 Keatings VM, Jatakanon A, Worsdell M, et al. Effects of inhaled and oral glucocorticoids on inflammatory indices in asthma and COPD. Am $\mathcal{F}$ Respir Crit Care Med 1997; 155:542-8.

13 Massaro AF, Gaston B, Kita D, et al. Expired nitric oxide levels during treatment of acute asthma. Am $\mathcal{F}$ Respir Crit Care Med 1995;152:800-3.

14 Kharitonov SA, Yates DH, Barnes PJ. Inhaled glucocorticoids decrease nitric oxide in exhaled air of asthmatic patients. Am F Respir Crit Care Med 1996;153:454-7.

15 Kharitonov SA, Yates DH, Chung KF, et al. Changes in the dose of inhaled steroid affect exhaled nitric oxide levels in asthmatic patients. Eur Respir f 1996;9:196-201.

16 Quanjer PhH, Tammeling GJ, Cotes JE, et al. Lung volumes and forced ventilatory flows. Eur Respir f 1993;6:5-40.

17 Sterk PJ, Fabbri LM, Quanjer PhH, et al. Airway responsiveness: standardized challenge testing with pharmacological, physical and sensitizing stimuli in adults. Eur Respir f 1993;6:53-83.

18 Fahy J, Lui J, Wong H, et al. Cellular and biochemical analysis of induced sputum from asthmatic and from healthy subjects. Am Rev Respir Dis 1993;147:1126-31.

19 De Gouw HWFM, Grünberg K, Schot R, et al. The relationship between exhaled nitric oxide and airway hyperresponsiveness following experimental rhinovirus infection in asthmatic subjects. Eur Respir F 1998;11:12632.

20 Kraan J, Koëter GH, Van der Mark ThW, et al. Changes in bronchial hyperreactivity induced by 4 weeks of treatment with antiasthmatic drugs in patients with allergic asthma: a comparison between budesonide and terbutaline. F Allergy Clin Immunol 1985;76:628-36.

21 Jatakanon A, Lim S, Chung KF, et al. Correlation between exhaled nitric oxide, sputum eosinophils, and methacholine responsiveness. Am F Respir Crit Care Med 1997;155:A819.

22 Baraldi E, Maestrelli P, Semenzato R, et al. Comparison of exhaled NO values, eosinophil counts in the induced sputum and eosinophil cationic protein (ECP) in asthmatic children. Eur Respir f 1997;10:158s.

23 Wallen N, Kita H, Weiler D, et al. Glucocorticoids inhibit cytokine-mediated eosinophil survival. F Immunol 1991; 147:3490-5.

24 Hallswoth MP, Litchfield TM, Lee TH. Glucocorticoids inhibit granulocyte-macrophage colony-stimulating inhibit granulocyte-macrophage colony-stimulating factor-1 and interleukin-5 enhanced in vitro surv
human eosinophils. Immunology 1992;75:382-5.

25 Corrigan CJ, Hamid Q, North J, et al. Peripheral blood CD4 but not CD 8 T-lymphocytes in patients with exacerbations of asthma transcribe and translate messenger RNA encoding cytokines which prolong eosinophil survival in the context of a Th2-type pattern: effect of glucocorticoid therapy. Am $\mathcal{F}$ Respir Cell Mol Biol 1995;12:567-78.

26 Moncada S, Palmer RMJ, Higgs EA. Nitric oxide: pathophysiology and pharmacology. Pharmacol Rev 1991; 42:109-42.

27 Haley KJ, Drazen JM. Inflammation and airway function in asthma. What you see is not necessarily what you get. $A m \mathcal{F}$ Respir Crit Care Med 1998;157:1-3.

28 Lange P, Parner J, Vestbo J, et al. A 15-years follow-up of ventilatory function in adults with asthma. $N$ Engl $\mathcal{F}$ Med 1998;339:1194-200

29 Haahtela T, Järvinen $M$, Kava T, et al. Effects of reducing or discontinuing inhaled budesonide in patients with mild asthma. N Eng F Med 1994;331:700-5.

30 Barnes PJ, Kharitonov SA. Exhaled nitric oxide: a new lung function test. Thorax 1996;51:233-7.

31 Sont JK, Willems LNA, Bel EH, et al and the AMPUL Study Group. The clinical control and histopathological outcome of asthma using airway hyperresponsiveness as an additional guide of long-term treatment. Am $\mathcal{F}$ Respir Crit Care Med 1999 (in press). 